\title{
Monitoring Riparian Restoration Efforts in the Willamette Valley
}

\author{
Jessica Scott*, Johnmichael Lahtinen, Erin Engbeck, Terri Berling, Katie Ferra, \\ Alexander Gregory, Natalie Otto, Garret Pemstein, Wayland Tan, Gail Tinkham, \\ Environmental Studies**
}

\begin{abstract}
The 10-student Environmental Leadership Program team, Wetlands Wildlife, collected data on Delta Ponds, a 61-hectare waterway site owned by the City of Eugene bordering the Willamette River. We used two primary monitoring activities to collect data on riparian communities and restoration efforts, focusing specifically on vegetative community type as well as biological indicators of survival and vigor. Six vegetative communities were subject to monitoring: Upland, Riparian, Wetland Transition, Emergent, Himalayan Blackberry and Recent Restoration. We collected data using protocols that were tailored to species identification, community mapping and vegetation health assessment. Overall, we found that the health of Delta Ponds appears to be improving; through community mapping we found a general increase in percent area cover for almost all target communities, with the Upland community displaying the largest increase, growing from $9 \%$ to $21 \%$ of the area surveyed. However, Emergent and Himalayan Blackberry actually decreased in percent area cover. We believe this general increase is due to extensive removal of the invasive Himalayan Blackberry (Rubus bifrons). Throughout monitoring efforts it was observed that there was a relatively high survival rate of riparian plantings with both tree and shrub plantings exhibiting a trend in growth over time. Various monitoring efforts including vegetation community mapping and riparian vigor monitoring were used to assist the City of Eugene in the prioritization of management resources and will serve as a baseline for future restoration efforts.
\end{abstract}

\section{INTRODUCTION}

Complex networks of side-channels with healthy native riparian and aquatic vegetation help to filter water, buffer flooding, provide erosion control and recharge groundwater as well as provide habitat for native fish and wildlife. These are just a few of the ecosystem services a healthy wetland area can provide. In addition, wetland areas, such as Delta Ponds, help to provide not

\footnotetext{
*Please direct correspondence to jscott2@uoregon.edu. See pages 13-14 for[Dcomplete list of author biographies.

${ }^{* *}$ Authors are members of the University of Oregon Environmental Leadership Program, a collaborative, interdisciplinary service-learning program housed in the University of Oregon Environmental Studies Program. For more information, visit http://envs.uoregon.edu/elp_program/. To access the ELP Stream Stewardship Team website, visit https://sites.google.com/site/elp2012streamstewardship/home.
} 
only key habitat for native fish and wildlife, but also educational and recreational benefits for the general public.

If properly managed, riparian zones within a wetland system become sites of complex biodiversity and play an essential role in the overall health and success of restoration efforts (Naiman \& De'camps 1997). However, newly restored zones can be vulnerable to growth of invasive plant species such as Himalayan Blackberry (Rubus bifrons) and Reed Canarygrass (Phalaris arundinacea). Consequently, newly restored riparian zones must be actively monitored and managed until reaching a free-to-grow status so as to detect and correct problems of overcompetition by invasive species (Pasquale et al. 2011). Plantings are considered free-to-grow when they are taller than surrounding competing plants and no longer require release treatments (Massingill 2003).

Monitoring efforts were conducted for both native and invasive plant species within Delta Ponds in an effort to detect change in the biological dynamics occurring after restoration efforts by the City of Eugene. Changes were determined through reapplication and comparative evaluation of the methods and findings completed by the 2005 Delta Ponds Team (Davis et. al 2005). Vegetation community mapping was completed with the specific goal of observing community succession since 2005. Further riparian vegetation monitoring was completed for 2008 and 2010 plantings with the goal of supplying critical feedback on planting methods, protection and maintenance, as well as information on species and sources of planted stock within newly planted riparian benches. Such on-going monitoring can provide insight into growth rates, vigor, damage, canopy closure, stream shading, and/or estimated time of free-to-grow status (Massingill 2003). In summary, the overarching goal of these two monitoring activities was to provide our community partners with feedback on completed restoration efforts and recommendations for future habitat improvements based upon the team's findings.

\section{STUDY AREA}

Delta Ponds is a 61-hectare waterway located in northeast Eugene, Oregon, just off of Goodpasture Island Rd (Figure 1). Historically, the area provided a floodplain that surrounded much of the Willamette River, yet through human activities, such as urbanization and industrialization, the river's complexity was altered and simplified. In the 1950's and 1960's, the once-historic floodplains were converted to gravel mines. Through this prolonged extraction, the local ecology was damaged and small networks of ponds were created, isolated from the flow of the Willamette (City of Eugene 2012). After being purchased in the late 1970's by the City of Eugene, the former gravel quarry sat unmanaged for decades, developing a wetlands ecosystem that consisted of both native and invasive species. Between 2004 and 2012 the City of Eugene began an eight-year enhancement effort of invasive species control and native plantings. Projects also included establishing connectivity between the ponds and the Willamette River, which involved removal of invasive species such as Himalayan Blackberry from over 24 hectares of land within the ponds. Work was also done to improve 8.04 kilometers of riparian benches by converting steep banks, left by the process of gravel extraction, into gentle slopes. This was achieved through the planting of 75,000 native grasses, shrubs and trees along newly restored 
embankments and zones cleared of Himalayan Blackberry (Delta Ponds Floodplain Restoration Project Summary, 2012). The overall motive for the restoration of Delta Ponds was to create and enhance habitat for juvenile Chinook Salmon (Oncorhynchus tshawytscha) and the Western Pond Turtle (Actinemys marmorata) with the intention that restoration would benefit other species as well, such as native amphibians.

Figure 1: Aerial photo of Delta Ponds Eugene, Oregon. Areas 1-3 indicate distinct sections separated by Goodpasture Island Road and Delta Highway.

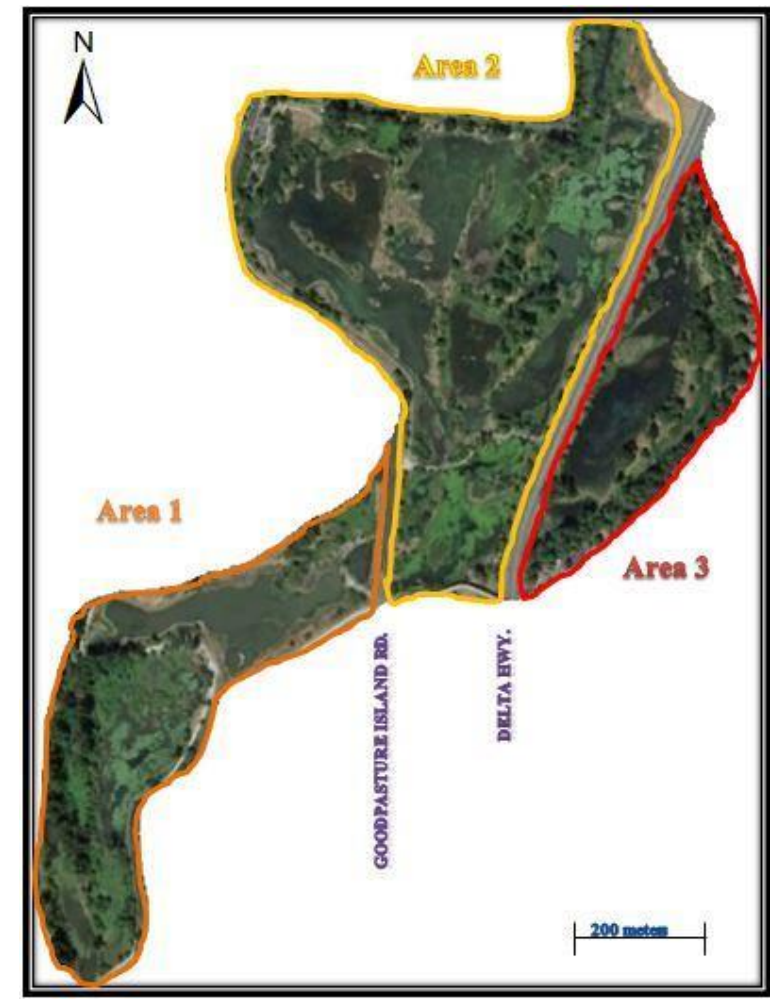

\section{VEGETATION COMMUNITY MAPPING}

\subsection{METHODS}

In an effort to examine the change in vegetation since 2005, we followed the methods provided by the 2005 Delta Ponds Team, delineating the area covered by six major vegetation communities: Upland, Riparian, Wetland Transition, Emergent Vegetation, Himalayan Blackberry and Recent Restoration communities (Davis et al. 2005). For consistency, the entirety of Delta Ponds was surveyed, including non-city property primarily following Delta Highway. Using aerial photos with clear plastic overlays, teams of two to three people outlined community boundaries through ground-based mapping, using a minimum mapping area of $5 \mathrm{~m}^{2}$. However, due to lack of accessibility in some areas, community identification was completed remotely using 2012 Google Earth aerial photos, assessing an area no greater than $10 \%$ of the total area surveyed. Community 
boundary outlines were then transferred to Google Earth Pro for calculation of total area encompassed as well as the calculation of area subsections 1, 2 and 3 for each community type. In cases of overlapping or mixed community types, identification was completed based upon visual interpretation of the dominant community present. In an effort to more extensively survey the entirety of Delta Ponds our community boundary inclusion differed from the 2005 protocols. Community boundaries were mapped in 2005 based upon overstory characteristics while our methods evaluated both overstory and understory characteristics, examining shrub layer and reproduction in addition to canopy cover (Davis et al. 2005). The six communities were defined by dominant plant species as follows:

a. Upland Community: The Upland community occupies the higher and drier terrain around Delta Ponds and primarily consists of Bigleaf Maple (Acer macrophyllum), Oregon White Oak (Quercus garryana), Oregon Ash (Fraxinus latifolia), White Alder (Alnus rhombifolia) and Madrone (Arbutus menziesii).

b. Riparian Community: This community grows around the perimeter of ponds in wetter soil, lower in elevation than the Upland community. Black Cottonwood (Populus trichocarpa) and Red Alder (Alnus rubra) dominate the community though Oregon Ash, White Alder, and Pacific Willow (Salix lucida) can also be found.

c. Wetland Transition Community: Occupying pond edges and lowlands that are generally submerged during the winter but not summer months, the Wetland Transition community primarily consists of various species of willows (Salix ssp).

d. Emergent Vegetation Community: This community occupies wet lowlands seasonally submerged from September to May and includes sedges (Carex sp.), rushes (Juncus sp.) and Yellow Flag Iris (Iris pseudacorus).

e. Himalayan Blackberry Community: This community consists of an invasive blackberry species that can form monocultures. The Himalayan Blackberry can occupy a variety of ecological niches and as such, is found from the drier Upland area down to the Wetland Transition zone.f. Recent Restoration Community: Since 2004 the City of Eugene funded the planting of over 75,000 native tree and shrub saplings. Within each planting zone three to eleven different species, dependent on community, were planted and included various species of willows, Black Cottonwood, Red-osier Dogwood (Cornus sericea) and other previously listed species.

\subsection{RESULTS}

Extensive ground-mapping efforts were made to encompass the entirety of areas 1-3, surveying a total area of 27.2 ha (Table 1). Every community, Himalayan Blackberry aside, increased significantly in area, ranging from $413 \%-1130 \%$ increases. Such high area increases do not accurately reflect growth as the 2005 baseline data used for comparison encompassed a much smaller area, including only 5.45 ha of the area we surveyed (Table 1). A more accurate reflection 
of community growth is observed through community percent distribution of the area surveyed (Figure 2).

Table 1: Vegetation community total area for 2005 and 2013 surveys.

\begin{tabular}{llllllllll}
\hline $\begin{array}{l}\text { Vegetation } \\
\text { Community }\end{array}$ & $\begin{array}{l}\text { Total Area } \\
\mathbf{2 0 0 5}(\mathbf{h a})\end{array}$ & $\begin{array}{l}\text { Total Area } \\
\mathbf{2 0 1 3}(\mathbf{h a})\end{array}$ & $\begin{array}{c}\text { Area 1 } \\
\mathbf{2 0 0 5}\end{array}$ & $\begin{array}{c}\text { Area 1 } \\
\mathbf{2 0 1 3}\end{array}$ & $\begin{array}{c}\text { Area 2 } \\
\mathbf{2 0 0 5}\end{array}$ & $\begin{array}{c}\text { Area 2 } \\
\mathbf{2 0 1 3}\end{array}$ & $\begin{array}{c}\text { Area 3 } \\
\mathbf{2 0 0 5}\end{array}$ & $\begin{array}{c}\text { Area 3 } \\
\mathbf{2 0 1 3}\end{array}$ \\
\hline Upland & 0.50 & 5.64 & 0.12 & 1.14 & 0.29 & 2.21 & 0.09 & 2.30 \\
Riparian & 1.70 & 8.84 & 0.73 & 4.18 & 0.63 & 2.76 & 0.35 & 1.89 \\
$\begin{array}{l}\text { Wetland } \\
\text { Transition }\end{array}$ & 1.07 & 6.76 & 0.47 & 2.97 & 0.43 & 2.85 & 0.17 & 0.95 \\
\hline Emergent & 0.51 & 2.09 & 0.22 & 0.82 & 0.27 & 0.96 & 0.02 & 0.31 \\
\hline Blackberry & 1.67 & 0.64 & 0.57 & 0.37 & 0.88 & 0.28 & 0.22 & 0.00 \\
Restoration & $\mathrm{n} / \mathrm{a}$ & 3.24 & $\mathrm{n} / \mathrm{a}$ & 0.96 & $\mathrm{n} / \mathrm{a}$ & 1.31 & $\mathrm{n} / \mathrm{a}$ & 0.97
\end{tabular}

Total Area Surveyed 2005 (ha): 5.45

Total Area Surveyed 2013 (ha): 27.22

Completed ground-based mapping delineated each community separately: Upland, Riparian, Wetland Transition, Emergent, Himalayan Blackberry and Restoration in order to display spatial relations throughout Delta Ponds. Those that displayed the greatest change were the Upland, Himalayan Blackberry and restoration communities (Figures 3-5). Based on observations, upland communities were observed as having the largest increase in relation to area surveyed (Figure 2). In contrast, the Himalayan Blackberry communities had decreased, covering $39 \%$ of its total former area. 
Figure 2: Vegetation community percent distribution 2005-2013.

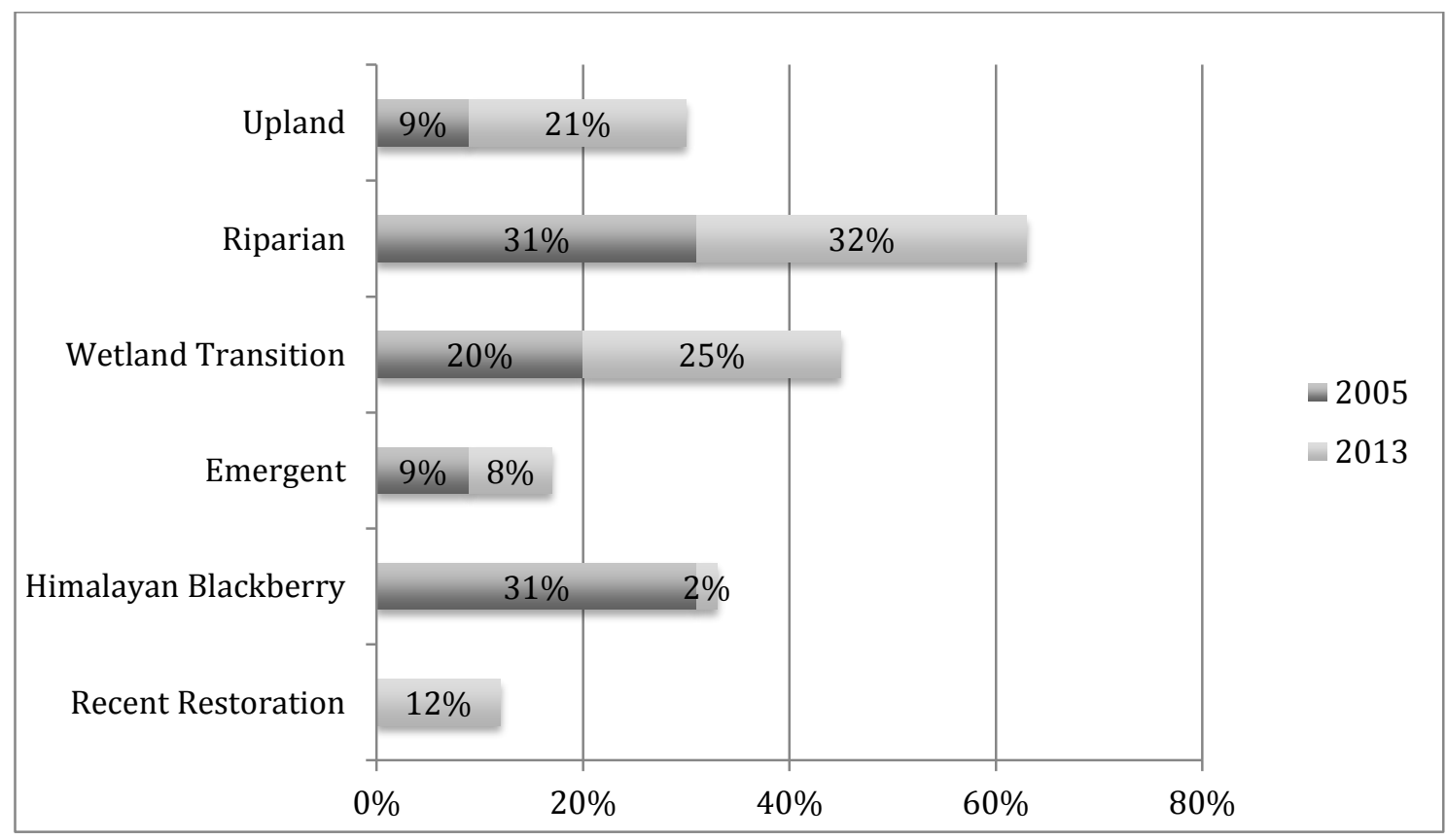

The majority of restoration efforts, in regards to planted areas, began after the 2005 mapping effort. Since the majority of plantings occurred after the initial mapping, Recent Restoration community areas were not mapped and our 2013 data serves as a baseline for future monitoring and restoration of riparian zones. Mapping of the Recent Restoration community revealed that this community encompasses $12 \%$ of the area surveyed (Figure 2). The remaining communities (Riparian, Wetland Transition and Emergent) were found to remain somewhat stable, exhibiting similar proportions to those of 2005 surveying efforts (Figure 2).

Figure 3: Upland vegetation community mapping boundaries for 2013 (right) and 2005 (left).
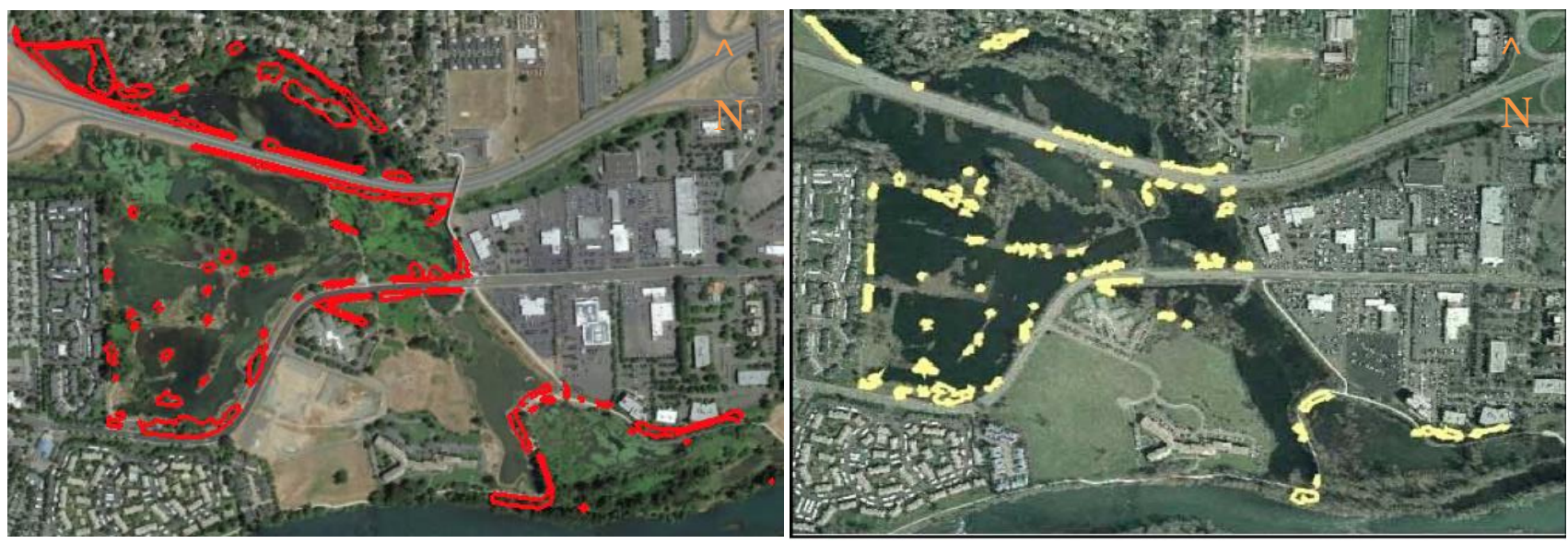
Figure 4: Himalayan Blackberry vegetation community mapping boundaries for 2013 (right) and 2005 (left).
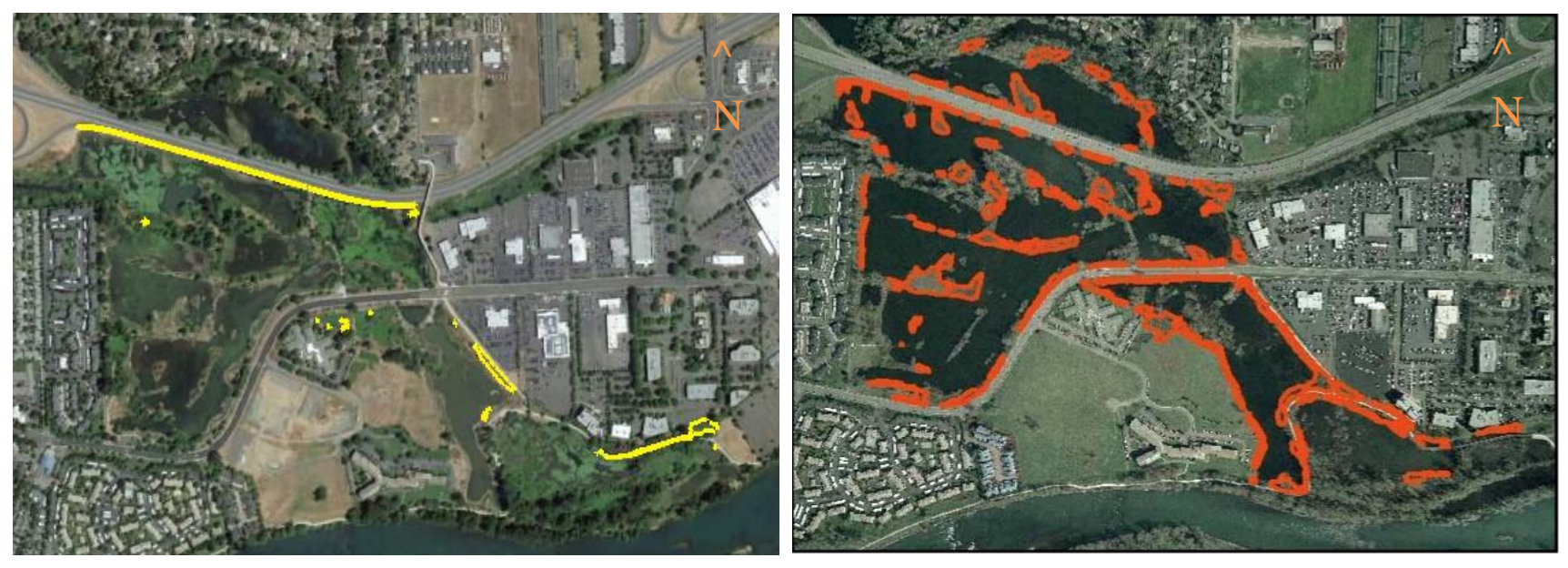

\subsection{DISCUSSION}

Due to extensive efforts by the City of Eugene, there has been a significant decrease in the proportion of area covered by invasive Himalayan Blackberry since 2005. As of 2013, the largest areas of remaining Himalayan Blackberry were located along the Delta Highway as well as by man-made paths; this coincided with 2005 findings (Figure 4). It should be noted that the Himalayan Blackberry contained within the property of the City of Eugene is substantially lower since part of the surveyed area along Delta Highway included lands owned and managed by Lane County. Because of this, the percent decrease in Himalayan Blackberry on City property is actually much lower. The Upland community displayed the largest relative increase (Figure 2) and often occurred alongside Delta Highway and man-made paths, much like the Himalayan Blackberry community (Figure 3). It is probable that due to reductions in Himalayan Blackberry communities, an increase in the area recognized as Upland resulted from encompassing former Himalayan Blackberry boundaries (Figure 4).

\section{RIPARIAN VIGOR MONITORING}

Between the years of 2008 and 2012, the City of Eugene conducted two major planting projects to vegetate the new riparian benches. In 2008, a contractor was hired to plant and maintain approximately 16,000 plants of various species spanning Emergent, Wetland 
Transition, Riparian and Upland Figure 6: Monitoring plot locations. communities. All plantings were completed between November 2008 and March 2009, and the contractor was responsible for maintaining all plants until September 30, 2010. A survival rate of $80 \%$ is considered optimal. However, due to a lack of watering at the most pertinent growth stage of the plantings, this percent survival was not met (City of Eugene, unpublished data). This was followed by a second contract in 2010 that called for the planting and maintenance of over 30,000 native plants (City of Eugene, unpublished data). Following the end of the first growing season, the City of Eugene conducted monitoring to evaluate the survival of the plantings to determine whether or not the $80 \%$ survival requirement was met.

Though plantings spanned a multitude of community types, monitoring efforts focused Plots originally monitored in 2009: 2
and 5. Plots originally monitored in
2011: 12 and 14.

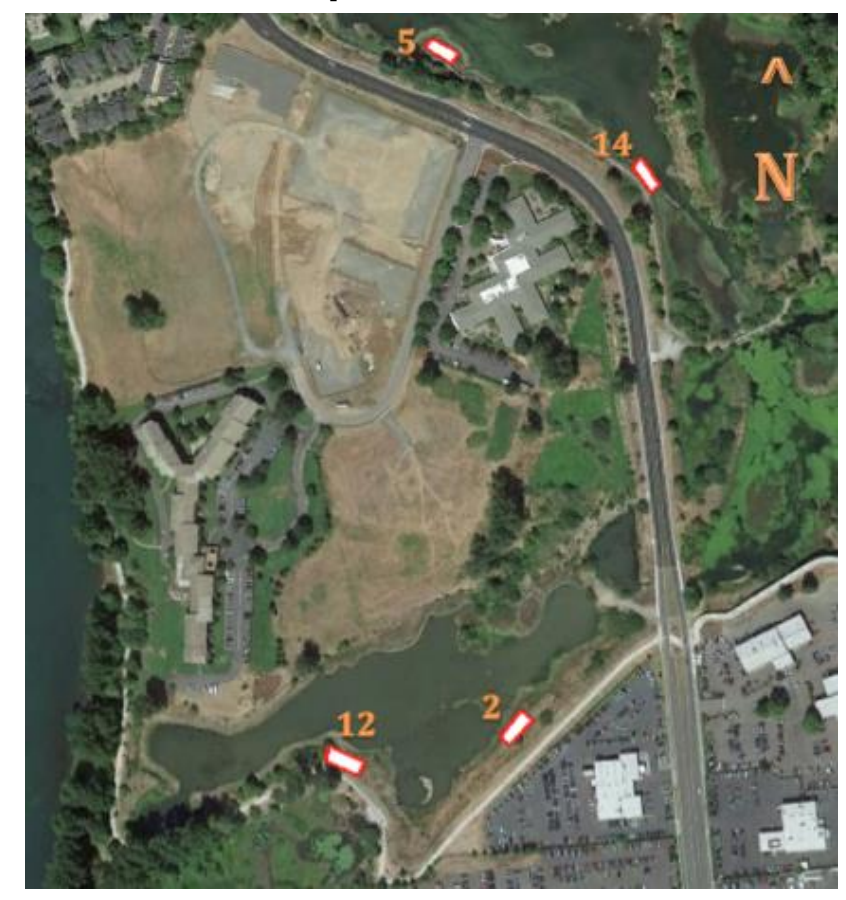
upon Wetland Transition and Riparian plantings located in newly restored riparian benches, including various species of willows, Red-osier Dogwood and Pacific Ninebark (Physocarpus capitatus). Implementation of our baseline monitoring relied primarily upon measurements of vigor. However, comparison of 2008 and 2010 planting data allowed for qualitative evaluation of growth and survival. Comparisons of future monitoring with baseline data will provide growth rates, changes in vigor, survival and help to identify on-going maintenance needs.

\subsection{METHODS}

The team completed riparian vigor monitoring for a randomly-selected subset of plots monitored by the City of Eugene in 2009 and 2011. As exact locations for previous plots were not recorded, aerial photos were used to approximate site locations. Four plots in total were randomly selected for monitoring; Plots 2 and 5 from 2009 monitoring and plots 12 and 14 from 2011 monitoring (Figure 6). Plots were established to include an area of $5 \mathrm{~m} \mathrm{x} \mathrm{30m.} \mathrm{Starting} \mathrm{with} \mathrm{the}$ southwest corner, pins were placed at each corner and connected by flagging tape to clearly mark plot boundaries.

After establishing plots, teams of four to five people surveyed the area, moving plant by plant and evaluating several key aspects for future evaluations of growth, vigor and survival. These variables included: species identification; live/dead determination; height (trees) or height class (shrubs); live crown height (trees); stem class (shrubs); level of brush and grass competition; protection type; and damage type, level and source (ELP Riparian Planting Monitoring Protocols, 2013). To determine height class for shrubs, the highest living part of the plant was measured and 
recorded based on the following height classes 1 through $6:<0.3 \mathrm{~m}, 0.3-0.6 \mathrm{~m}, 0.6-1.2 \mathrm{~m}, 1.2-1.8$ $\mathrm{m}, 1.8-2.4 \mathrm{~m}, 2.4+\mathrm{m}$. Stem class was determined by the number of stems present on the shrub (ELP Riparian Planting Monitoring Protocols, 2013). Trees were measured for live crown height, the distance from the uppermost live leader to the lowest live branch (USFS 2013). Brush competition was based on proximity and estimated amount of direct shading over the plant, ranging from o (no brush competition) to 3 (brush within $0.6 \mathrm{~m}$ and shading $>51 \%$ ). Grass competition was recorded on a scale of o to 3 , measuring the distance from plant stem to continuous sod within $45 \mathrm{~cm}$. Values were defined as no continuous sod and continuous sod within $16 \mathrm{~cm}$ respectively (ELP Riparian Planting Monitoring Protocols, 2013).

\subsection{RESULTS}

Surveys showed that the majority of plantings monitored in both 2008 and 2010 were various species of willow. Unable to identify the specific species for these plantings they were put into the general category of willows. Due to damage and the inability to identify some plants there were unidentified species recorded in all plots. The 2008 plots consisted of willows, Red-osier Dogwood, Pacific Ninebark, Common Snowberry, Black Cottonwood and Red Alder. The 2010 plantings monitored were predominantly willows, but other riparian species such as Red-osier Dogwood, Pacific Ninebark, and Black Cottonwood were identified.

\section{Table 2: Planting total for shrub and tree species monitored in 2008 and 2010 plots.}

\begin{tabular}{llllll}
\hline Shrubs & $\begin{array}{l}\mathbf{2 0 0 8} \\
\text { Total }\end{array}$ & $\begin{array}{l}\mathbf{2 0 1 0} \\
\text { Total }\end{array}$ & Trees & $\begin{array}{l}\text { 2008 } \\
\text { Total }\end{array}$ & $\begin{array}{l}\mathbf{2 0 1 0} \\
\text { Total }\end{array}$ \\
\hline Willows & 121 & 65 & Black Cottonwood & 5 & 4 \\
Red-osier Dogwood & 9 & 12 & Red Alder & 1 & O \\
Common Snowberry & 2 & 0 & & & \\
Pacific Ninebark & 6 & 1 & & & \\
Douglas' Spiraea & 0 & 7 & & & \\
\hline
\end{tabular}

A total of 152 shrubs and trees were monitored in the two 2008 plots with the dominate species being willow (Table 2). Eight plantings were unidentifiable. Of the 138 shrubs monitored, 42 were classified as mature with the others falling under the category of young or saplings. These plots had quite a bit of brush and grass competition and also exhibited some amounts of plant damage primarily located along the leaves. The damage appeared to be from insects and drought furthermore, the shrubs with the highest damage were willows. All six trees were alive and showed no signs of damage from insects or drought. Five trees had cages and one had vexar tubing for protection. 
Table 3: Average height for tree species monitored in 2008 and 2010 plots.

\begin{tabular}{lll}
\hline Species & $\begin{array}{l}\text { Average Height (m) } \\
\mathbf{2 0 0 8} \text { Plots }\end{array}$ & $\begin{array}{l}\text { Average Height (m) } \\
\mathbf{2 0 1 0} \text { Plots }\end{array}$ \\
\hline Black Cottonwood & 1.72 & 0.96 \\
Red Alder & 0.99 & ------ \\
\hline
\end{tabular}

Of the 90 plants monitored from the two 2010 plots, Willow was still the dominate species with 65 plants monitored (Table 2). Two unidentifiable plantings were also found during monitoring. Only five of the 84 shrubs were mature, with the rest being young or saplings. Compared to the 2008 plots, there was very little brush and grass competition in the 2010 plots. These plots had more overall damage present, not only on leaves but also along the branches and stems. This damage was attributed to disease, drought, physical damage and insect damage. There was generally no protection for plantings, however, we did find two with cages. Of the four Black Cottonwoods, two were dead, and only one had vexar tubing for protection.

Table 4: Average height class for shrub species monitored in 2008 and 2010 plots .

\begin{tabular}{lll}
\hline Species & Average Height Class & $\begin{array}{l}\text { Average Height Class } \\
\mathbf{2 0 0 8} \text { Plots }\end{array}$ \\
Willows & 3.17 & 2.42 \\
Red-osier Dogwood & 2.70 & 2.15 \\
Common Snowberry & 2.50 & ----- \\
Pacific Ninebark & 2.67 & 2.00 \\
Douglas' Spiraea & ----- & 2.29 \\
\hline
\end{tabular}

\subsection{DISCUSSION}

Through monitoring growth and vigor of our selected plots, it became evident that the majority of plants were alive with minimal damage. A total of 11 dead plants were counted, 9 of which were located in the 2008 plots, inferring high survival overall with an attrition rate of only a few plants dying per year. Wetland Transition and Riparian plantings from 2008 had an average survival rate of $66 \%$ when monitored in 2009. This did not meet the City's $80 \%$ survival rate requirement and the contractor completed additional plantings to achieve the required survival rate (City of Eugene unpublished data, 2010). 2008 plots are now showing a higher percentage of survival, fitting the general pattern of increased survival once plantings are established.

Lack of watering by the contractor responsible for the 2010 plantings lead to more replanting of various species and could have affected the number of species found in these plots. The first summer after planting is the most crucial time for new plantings (City of Eugene, unpublished data). Once plants' roots reach the water table, survival rates tend to be very high. Survival itself is a coarse indicator of success. Many plants can survive for several years with poor vigor and 
minimal growth rates. Thus it is important to take into consideration vigor, overall plant health and appearance before making adaptive management decisions.

In general the 2008 and 2010 plots display low levels of overall damage. Damage found in the 2008 plots was relatively low, with classification of less than $10 \%$, mainly found on leaves due to insects or drought. Along with damage, growth and vigor are important characteristics to observe in restoration areas. Growth is measured until stocks are considered free-to-grow and taller than the surrounding competing plants (Massingill 2003). All living plants monitored in both the 2008 and 2010 plots showed a positive growth trajectory by exhibiting higher average height or height class when comparing 2008 to 2010 (Tables 3 and 4). Vigor is more difficult to quantify but is critical to the success of a project. Vigorous trees can better tolerate disease and drought, as well as become free-to-grow faster (Massingill 2003). Since most of the plants in both plots showed growth and low damage, it reflects their suitability to the site, which will help in tailoring future planting decisions.

\section{RECOMMENDATIONS AND MANAGEMENT IMPLEMENTATIONS}

Restoration efforts by the City of Eugene have been largely successful and our data will inform future monitoring and management activities. Extensive blackberry removal has greatly reduced the overall percentage of Himalayan Blackberry bushes that made a distinct vegetative community at Delta Ponds (Figure 2). However, during ground-mapping efforts it was noted that several areas, specifically the less accessible peninsulas of Area 2, have new blackberry shoots growing. As of now, these shoots are too small to be accounted for in the vegetative community mappings, but if they are not addressed it will only be a few years before large areas of riparian vegetation are covered in blackberry bushes once again.

Improvement of habitat will be beneficial to fish and wildlife populations, but reduction of human-caused degradation is equally important in maintaining the biological integrity of Delta Ponds. Stricter measures to discourage off-trail use of Delta Ponds by pedestrians, anglers and unauthorized campers would further reduce this issue, as well as reduce disturbance of flora and fauna while decreasing the likelihood of future invasive species introduction. Vegetation communities adjacent to makeshift paths throughout the area are especially sensitive to human interaction and could benefit from the construction of more fencing.

\section{ACKNOWLEDGEMENTS}

Restoration efforts by the City of Eugene have been largely successful and our data will inform future monitoring and management activities. Extensive blackberry removal has greatly reduced the overall percentage of Himalayan Blackberry bushes that made a distinct vegetative community at Delta Ponds (Figure 2). However, during ground-mapping efforts it was noted that several areas, specifically the less accessible peninsulas of Area 2, have new blackberry shoots growing. As of now, these shoots are too small to be accounted for in the vegetative community mappings, but if they are not addressed it will only be a few years before large areas of riparian vegetation are covered in blackberry bushes once again. 
Improvement of habitat will be beneficial to fish and wildlife populations, but reduction of human-caused degradation is equally important in maintaining the biological integrity of Delta Ponds. Stricter measures to discourage off-trail use of Delta Ponds by pedestrians, anglers and unauthorized campers would further reduce this issue, as well as reduce disturbance of flora and fauna while decreasing the likelihood of future invasive species introduction. Vegetation communities adjacent to makeshift paths throughout the area are especially sensitive to human interaction and could benefit from the construction of more fencing.

\section{WORKS CITED}

Boulay, P. 2013. Wetlands Wildlife Riparian Planting Monitoring Protocols. University of Oregon Environmental Leadership Program, Eugene, Oregon.

City of Eugene. "City Facilities." City of Eugene. Web. 1 Jan. < $\underline{\text { http://www.eugene- }}$ or.gov/facilities/Facility/Details/133>.

City of Eugene, 2012. Delta Ponds Restoration Project Summary 2012. Eugene, OR. Available from http://www.eugene-or.gov/DocumentCenter/Home/View/5890.

Davis, D., H. Harguth, M. Jones-Romansic, R. Zimlich, and K. Darby. 2005. Delta Ponds: University of Oregon Service Learning Program in partnership with the City of Eugene. University of Oregon, Eugene, Oregon. Available from http://www.google.com/url?sa=t\&rct=j\&q=\&esrc=s\&source=web\&cd=3\&ved=oCDwQFjAC \&url=http\%3A\%2F\%2Fpages.uoregon.edu\%2Fecostudy\%2Felp\%2Fpdfs.html\%2FDelta\%25 20Ponds\%2520Report.pdf\&ei=SnwNUfuZHojWiAKisICgCg\&usg=AFQjCNExFe4G1PnoVV NGy1dlkvPpVcVSiA\&bvm=bv.41867550,d.cGE\&cad=rja (accessed March 2013).

Massingill, C. 2003. Coastal Oregon riparian silviculture guide. Coos Watershed Association, Charleston, Oregon.

Naiman, R. J., and H. De'camps. 1997. The ecology of interfaces: riparian zones. Annual Review of Ecological Systems 28: 621-658.

Pasquale, N., P. Perona, P. Schneider, J. Shrestha, A. Wombacher, and P. Burlando. 2011. Modern comprehensive approach to monitor the morphodynamic evolution of a restored river corridor. Hydrology and Earth System Sciences 14:1197-1212. DOI: 10.5194/hess-15-11972011.

U.S. Forest Service. 2013. Common stand exam user's guide, Chapter 4 Collecting and recording data. Natural Resource Information System: Field Sampled Vegetation. Available from http://www.fs.fed.us/nrm/documents/fsveg/cse user guides/Edited Chapter 4 CollectR ecord.pdf. 


\section{AUTHOR BIOGRAPHIES}

\section{Jessica Scott}

Jessi grew up in the high-mountain desert of Southeast Idaho exploring the hills and mountains of Idaho and Wyoming. Growing up she always liked playing in the dirt and finding out how things worked. She graduated in Winter 2014 with a degree in Environmental Science and a minor in Biology, after graduation she hopes to continue working with plants and wetland environments.

\section{Johnmichael Lahtinen}

Johnmichael was born and raised in Oregon, never missing a chance to enjoy the great outdoors. From a young age great importance was placed on travel and not only seeing the world we interact with but also helping to make it a sustainable environment for all. In his time at the University of Oregon he has worked to recognize this importance through international environmental stewardship and local restoration efforts. Johnmichael graduated in Spring 2013 with a degree in Environmental Studies.

\section{Erin Engbeck}

Erin grew up in Richmond, California where she spent many summers camping, fishing, and hiking within the Sierra Nevada mountain range. She is currently pursuing a degree in Environmental Studies and expects to graduate Summer 2014. After graduation she hopes to travel abroad, intent on working with various organizations focusing on conservation and restoration efforts.

\section{Terri Berling}

Terri grew up in Ludington, Michigan where she spent much of her youth hiking in the forest and playing in the dunes along Lake Michigan. Since then, she has lived in a variety of places, but now calls Oakridge, Oregon home. She is working towards a degree in Environmental Science with a minor in Biology, and hopes to work with aquatic creatures someday.

\section{Katie Ferra}

Katie grew up in Keizer, Oregon and was exposed at a young age to camping, fishing, hiking, and exploring. She began volunteer work of her own choice in middle school and moved up in the ranks to where she was leading other kids to do various community projects. Katie has a passion for old-growth and entomology, working in the wetlands as a coordinator is an ideal aspiration that she will attain. Katie is an Environmental Sciences major and hopes to get a minor in entomology as well.

\section{Alex Gregory}

Alex was born in Colorado but traded the snow for the rain at an early age and has never looked back. He has a passion for adventure that has landed him waist-deep in the ponds on more than one occasion. He is working towards bachelor's degrees in both Environmental Science and Biology, with a minor in Chemistry for good measure.

\section{Natalie Otto}

Natalie grew up in South West Portland, OR. Camping, swimming by rivers and hiking became some of her favorite past times. She wasn't yet ready to leave the green forests of Oregon, and decided to attend the University of Oregon majoring in Environmental Studies and minoring 
in Geology. She has traveled around the globe and hopes to spend a year or two traveling around South America contributing to various sustainability and restoration projects after graduation.

\section{Garrett Pemstein}

Garrett grew up in sunny Southern California and came to the University of Oregon for a change of scenery. He graduated Spring 2013 with a degree in Environmental Studies and a minor in Business Administration. In his free time he enjoys athletics, hiking, being with friends, and traveling. After graduation he hopes to travel and do some non-profit work in different countries.

\section{Wayland Tan}

Wayland was born and raised in the Springfield-Eugene area, graduating from Thurston High School. He spent 2 years at Lane Community College before attending the University of Oregon, pursuing a degree in Biology before switching it to Environmental Science. He graduated with a Bachelors of Science in spring 2013 and hopes to find employment in the fields of conservation/restoration. In his free time, he enjoys reading and practicing martial arts.

\section{Gail Tinkham}

Gail is a native Oregonian, growing up fishing, hunting and camping throughout Western Oregon. She is a flight instructor, and loves Oregon as much from the air as on the ground. Gail graduated in June 2013 with a major in Environmental Studies focusing in design and public policy. After graduation, she hopes to become involved in environmental health issues-both human and animal and secretly aspires for a chance to work with Dr. Tyrone Hayes on his amphibian research involving Atrazine. 